\title{
United States National Seismic Hazard Maps
}

he U.S. Geological Survey's
maps of earthquake shaking hazards provide information essential to creating and updating the seismic design provisions of building codes and insurance rates used in the United States. Periodic revisions of these maps incorporate the results of new research. Buildings, bridges, highways, and utilities built to meet modern seismic design provisions are better able to withstand earthquakes, not only saving lives but also enabling critical activities to continue with less disruption. These maps can also help people assess the hazard to their homes or places of work and can also inform insurance rates.

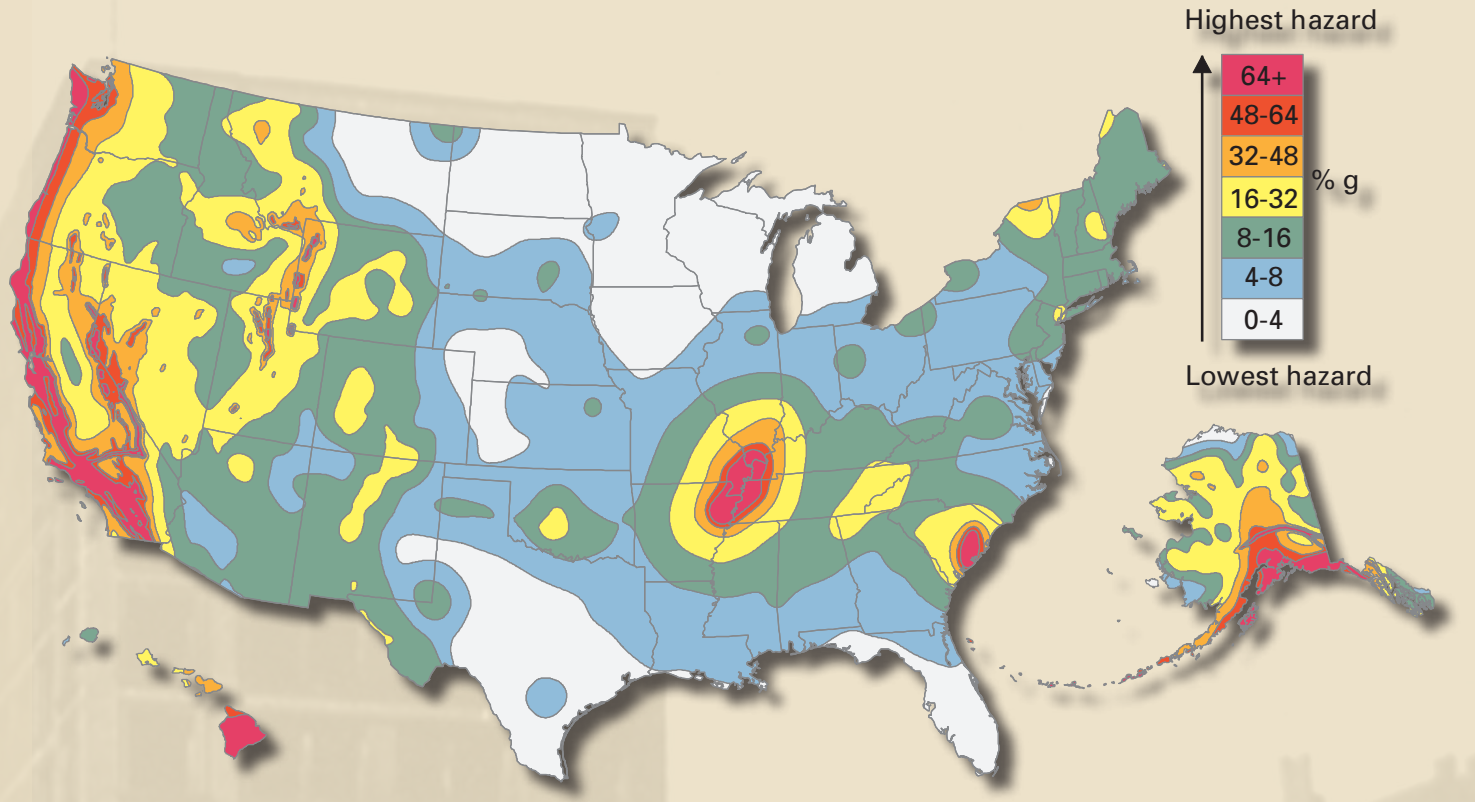

The 2008 U.S. Geological Survey National Seismic Hazard Maps for the United States are based on current information about the rate at which earthquakes occur in different areas and on how far strong shaking extends from earthquake sources. Colors on this particular map show the levels of horizontal shaking that have a 2-in-100 chance of being exceeded in a 50-year period. Shaking is expressed as a percentage of $\mathbf{g}$ ( $\mathrm{g}$ is the acceleration of a falling object due to gravity).
America's first line of defense against earthquakes is the construction of buildings that can withstand severe shaking. Cities and counties rely on the seismic design provisions in building codes to ensure that structures can resist the earthquakes that are probable in their region. The variations in the seismic threat across the country are depicted on maps in building codes as zones of different risk levels. These building code maps are based on more detailed maps, collectively known as the National Seismic Hazard Maps, prepared by the U.S. Geological Survey (USGS) with input from scientists and engineers at universities, State geological surveys, and the private sector.

The National Seismic Hazard Maps incorporate a wealth of geologic and seismologic information used to estimate the shaking, or ground motion, from earthquakes. In particular, the maps incorporate estimates of the magnitudes and locations of all likely earthquakes, how often these earthquakes occur, and the strength of ground shaking that they cause. The maps are time-independent, as they portray a long-term average hazard and are not affected by the time of the last earthquake rupture. This attribute makes the maps well suited for use in building codes, where the long-term life of a structure and its resilience to earthquake shaking must be considered.
The National Seismic Hazard Maps are revised periodically by the USGS to include new research results on earthquake faults, crustal deformation, and earthquake ground shaking. The timing of the updates is designed to coincide with the schedule for updates of model building codes. During the update process, USGS solicits recommendations for improvements from the earth science and engineering communities, prepares draft maps that are vetted regionally, and solicits both public and expert opinion in review of the maps before they are finalized. Producing these maps is a key responsibility of the USGS in the four-agency, congressionally established National Earthquake Hazards Reduction Program (NEHRP). The NEHRP agencies work cooperatively with appropriate national building codes and standards organizations to ensure that the most up to date and technically sound earthquake engineering design technology is available for use around the Nation. The four agencies-Federal Emergency Management Agency (FEMA), National Institute of Standards and Technology (NIST), National Science Foundation (NSF), and USGS - view the implementation of building codes as a central purpose of this partnership and the best means to ensure that buildings and other structures in local communities are adequately protected against natural hazards. 
Seismic hazard maps have many other applications. For example, the 2002 USGS National Seismic Hazard Maps are used as the basis of seismic design requirements for highway bridges nationwide. Such maps are also used by:

- Insurance companies to set property rates in various areas of the country.

- Federal Emergency Management Agency (FEMA) to plan the allocation of assistance funds for education and preparedness and improve risk assessments.

- Risk and loss modeling companies to estimate potential losses to a region or to a portfolio of assets.

- Civil engineers to estimate the stability and landslide potential of hillsides, and the liquefaction potential of strata underlying communities.

- U.S. Environmental Protection Agency to set construction standards that help ensure the safety of wastedisposal facilities.

A new series of National Seismic Hazard Maps was publicly released by the USGS in 2008. Each of these maps shows the severity of expected earthquake shaking for a particular level of probability. For example, the map on the front page shows levels of earthquake shaking that have a 2-in-100 chance of being exceeded in a 50-year period. The time period of 50 years is commonly used because it represents a typical building lifetime, while the 2-percent probability level is usually considered an acceptable hazard level for the building codes. This new series of maps also depicts shaking using a number of different measures that engineers can readily apply to designing earthquake-resistant buildings of different heights, which respond to different frequencies of ground motion.

The updated National Seismic Hazard Maps incorporate newly published seismic, geologic, and geodetic models that define the best available science on earthquake rates and associated ground shaking. These ground-motion models show the decay in ground shaking with distance from the earthquake source (attenuation), and incorporate the effects of varying soil type and faulting style. The updated attenuation models incorporate many recent earthquake strong-motion records and generally result in lower estimates of ground shaking than previous models. New fault studies, geologic maps, reflection and refraction surveys, and geodetic strain rate models provide insights into earthquake sizes and recurrence rates for crustal and subduction sources. This information was discussed with working groups, State geological surveys, Federal agencies, and other earth-science experts from industry and academia in revising the input models. The new ground-motion and earthquake source models result in similar or lower predicted ground motion across most of the United States compared to motion calculated in earlier versions of the hazard maps.

Through the continuing process of refining estimates of the shaking and earthquake hazard across the Nation and observing successes and failures in building design, scientists and engineers are laying the groundwork for communities to remain safer during future earthquakes. By improving the resilience to earthquake shaking of homes, office buildings, hospitals, highways, dams, and utilities, scientists and engineers also help to ensure that those communities are able to recover rapidly following a major temblor.

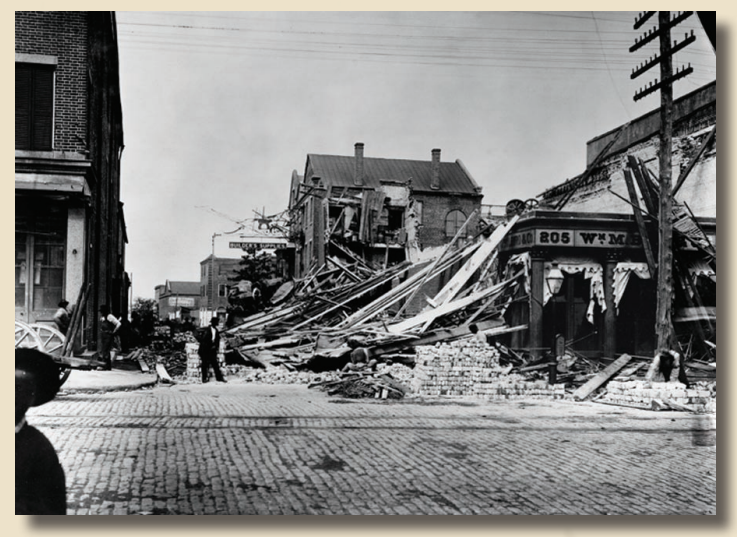

Charleston, South Carolina, Earthquake August 31, 1886. The worst earthquake wreck in Charleston. (USGS photo library). Photograph by J.K. Hillers.

\section{Building the Model Building Codes: The Role of Seismic Hazard Maps}

There is no single mandatory national building code or standard for designing and constructing buildings and other structures in the United States. Building codes are adopted and enforced by individual States and by local jurisdictions within the States. State or local building codes are usually based on a "model" building code or other voluntary consensus standards. State and local governments may either directly adopt the model code or adopt the code with amendments. Today, the model building code that is predominantly adopted in the United States is the International Building Code (IBC), promulgated by the International Code Council (ICC), a non-governmental organization. The ICC also promulgates other model codes that impact the building process, such as the International Residential Code (IRC). Some localities have also adopted the National Fire Protection Association (NFPA) 5000 Building Construction and Safety Code.

The IBC and its companion ICC documents form the basis of the building codes in 46 States and have been adopted by local governments within the remaining 4 States; thus, State and local building codes adopted throughout the United States share a common origin. As States and localities have based their codes upon the model codes, the performance of buildings constructed in accordance with the newer building codes has improved.

The four-agency National Earthquake Hazards Reduction Program (NEHRP) supports the development of seismic provisions in building codes by maintaining the quality of four documents that build on one another: 
- The NEHRP Recommended Provision for Seismic Regulations for New Buildings and Other Structures. This document presents the state of the art of earthquake engineering research and practice in a form usable by the engineering community, and provides a nationally applicable resource document for all model codes and standards. FEMA leads the effort to maintain this document, which since its inception in 1985 has been updated on a 3- to 5-year recurring cycle. USGS directly supports the update process by providing appropriate updated seismic ground motion maps and soil/site condition parameters that incorporate the latest seismological findings. USGS also prepares seismic design maps based on the hazard levels and other modifications recommended by technical committees participating in the update process. Appropriate basic (NSF-sponsored) and applied (NIST-sponsored) engineering research results are included in the updates. The document also serves the needs of the Federal Government as a baseline for executive orders related to Federal building design and construction.

- ASCE 7. The American Society of Civil Engineers (ASCE) supports the development on a 5-year cycle of the Minimum Design Loads for Buildings and Other Structures, known as ASCE 7. FEMA and USGS work with ASCE to ensure that ASCE 7 adequately addresses seismic loads and design in a manner that is "substantially equivalent" to guidelines recommended by the NEHRP Recommended Provisions.
- The International Codes and the NFPA 5000. Most State and local jurisdictions use the IBC and the IRC as the basis for their building code laws and regulations; a few local jurisdictions have adopted NFPA 5000. The IBC and NFPA 5000 adopt ASCE 7 by reference for most seismic design requirements, and the IRC incorporates NEHRP-based seismic requirements directly.

\section{Cooperating Agencies and Organizations}

American Assoc. of State Hwy. Transportation Officials American National Standards Institute American Society of Civil Engineers

Applied Technology Council

Building Officials and Code Administrators International Building Seismic Safety Council

State Geological Surveys

California Earthquake Authority

Environmental Protection Agency

Federal Emergency Management Agency

International Conference of Building Officials

Mid-America Earthquake Center

National Science Foundation

National Center for Earthquake Engineering Research

National Institute of Standards and Technology

National Oceanic and Atmospheric Administration

Pacific Earthquake Engineering Research Center

Southern Building Code Congress

Southern California Earthquake Center

Structural Engineers Association of California

Western States Seismic Policy Council

\section{NEHRP Impact on the Built Environment}

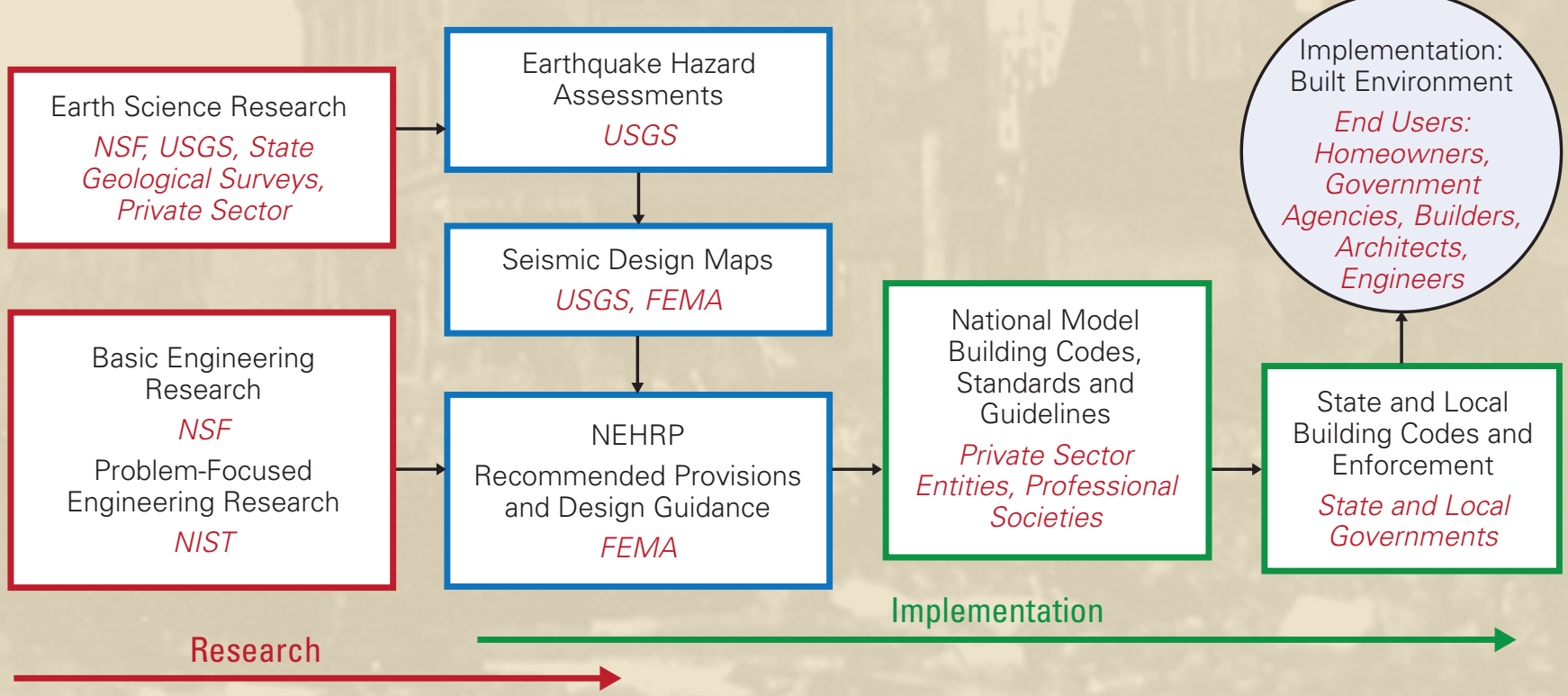

Flow chart of the Building Code Process. USGS provides both basic research and hazard information that is critical to development of seismic provisions in building codes. USGS works with other NEHRP agencies (FEMA, NIST, NSF) to ensure the most up to date and technically sound earthquake engineering design technology is available for use around the Nation. 


\section{USGS Earthquake Hazard Assessment Products and Tools}

\section{U.S. National Probabilistic Ground-Motion Maps}

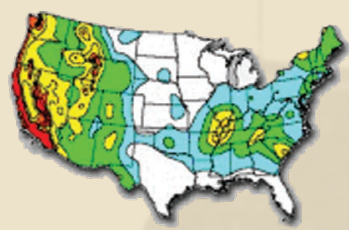

This Web site contains maps and associated input/output data and documentation for probabilistic hazard maps for the 48 Conterminous States, Alaska, Hawaii, and Puerto Rico.

\section{Hazard Mapping and Analysis Tools}

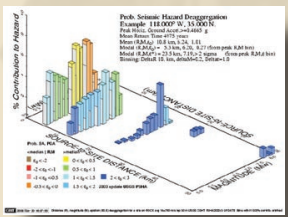

USGS offers a number of on-line Web tools that allow an individual to assess which sources pose the greatest hazard in a particular region, look up hazard values using latitude/longitude or Zip code, make customized USGS probabilistic hazard maps for an area of interest, map probability of a given magnitude within a certain distance from a site, and access computer software for seismic hazard analysis.

\section{Urban Probabilistic Ground-Motion Maps}

These maps show more detailed probabilistic seismic hazard maps for urban areas that take into account nearsurface geologic conditions, sedimentary basin structure, and directivity effects.

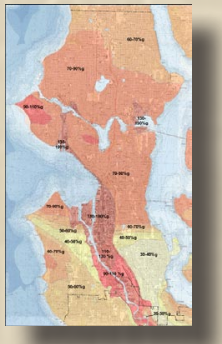

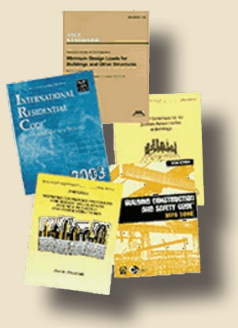

Seismic Design Values for Buildings

This Web site allows users to determine design ground motion at a site for various building codes, using latitude/ longitude or Zip code. In addition, one can display and download a hazard curve or uniform hazard spectrum for a site.

\section{U.S. Quaternary Fault and Fold Database}

This Web site contains information

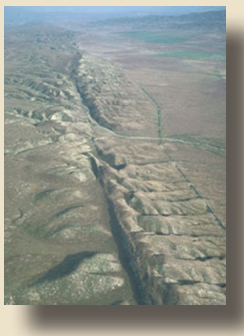
on faults and associated folds in the United States that are believed to be sources of M>6 earthquakes during the Quaternary (the past 1,600,000 years). Maps of these geologic structures are linked to detailed descriptions and references.

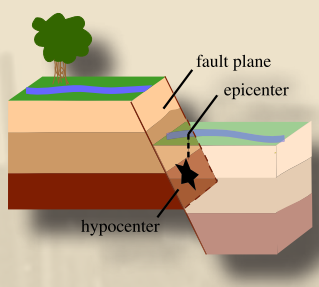

\section{Earthquake Hazards 101}

USGS provides a wealth of explanatory materials for the layperson, including information on concepts behind earthquake maps, the use of probability, what the maps mean, how they are made, and answers to frequently asked questions.

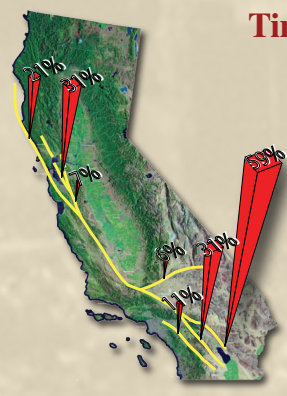

Time-Dependent Earthquake Probability Maps

These maps forecast the likelihood of an

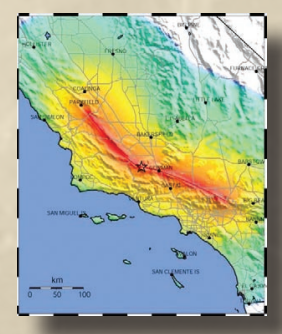

Maps predict the median level of ground shaking from a particular "scenario" event. They do not take into account the likelihood of that scenario occurring, but they are helpful when assessing the potential impact of a particular event. earthquake rupture occurring during an interval of time in the future. Time-dependent maps are considered research tools and are not currently applied in building codes.

\section{For Further Information}

To access these products and tools and for further information, see the Web site for the U.S. Geological Survey Earth Hazards Program at URL http://earthquake.usgs.gov/hazmaps/, and visit http://www.nehrp.gov or e-mail info@ nehrp.gov.

You may also contact Mark Petersen: mpetersen@usgs.gov. 